\title{
SNOEZELEN AND DEMENTIA: A CASE STUDY
}

\author{
Ramona Ribes \\ Maria José Cid \\ Noelia Llamas
}

\begin{abstract}
From the model of quality of life and person-centered care (Kitwood, 1997), we present a case study with the aim of evaluating the benefit of Snoezelen multisensory stimulation (SMS) in an 88-year-old subject with unspecified dementia, GDS6, and recurrent depressive disorder. For this purpose, a pretest-posttest design was chosen, with an intervention consisting of one weekly Snoezelen session for five weeks. To assess the effects of the intervention, a record of the physiological and behavioral profile of the person was used. The results include both the immediate effects of SMS and those after two hours. In conclusion, the Snoezelen intervention produced immediate and short-term benefits in terms of connection with the environment and behavioral adjustment in an elderly patient with advanced dementia.
\end{abstract}

\section{Keywords}

Snoezelen, dementia, person - centered care, multisensory stimulation, psychological and behavioral profile, intervention.

\section{Introduction}

Dementia is one of the most common health problems in older people. The WHO (2015 in ICD - 2010) estimates that it affects 50 million people in the world, and in the future the trend will increase to 80 million by 2030 and 152 million by 2050 . The most advanced stage of this neurodegenerative disease is characterized by cognitive and functional impairment, with behavioral alterations. This results in a deterioration in the quality of life of sufferers and is a major stressor for their caregivers.

Currently, non-pharmacological therapies (NPTs) are used as a complementary or alternative approach in interventions targeted at people with dementia. Snoezelen multisensory stimulation (SMS) is included in this type of therapy. SMS began 
in the Netherlands in the 1970s, and was first described by Hulsegge and Verhuel, (cited in $\mathrm{Cid}, 2010)$ in adults with severe disabilities. Currently, the Snoezelen intervention is applied in a wide variety of health problems, helping patients to improve their overall adaptation cognitively, physically, emotionally, and behaviorally (Cid, 2012).

In people with moderate to severe dementia, its benefits in terms of adaptive behavior have been demonstrated by increased patient well-being and quality of life (Sposito et al., 2016; Maseda et al. 2018,). Aznar-Calvo et al. (2019) describe the implementation of multisensory stimulation programs in Snoezelen rooms in people with dementia as a strategy to improve involvement and connection with the environment, in addition to reducing psychological and behavioral symptoms.

The methodology of intervention in Snoezelen rooms is included in the paradigm of Person-Centered Care (PCC) for dementia (Kitwood, 1997). Kitwood stresses the importance of empathizing with the subject and their needs and promoting their autonomy for as long as possible. PCC is, thus, a new way of understanding professional care, which aims to provide comprehensive personalized care. Jakob and Collier (2017) found that the characteristics professionals associated with a successful and effective Snoezelen space for people with dementia were: comfort, safety, meaningfulness of activities consistent with patient age, a relaxing sensory experience, a sense of control, and interaction to the greatest possible extent. In this regard, knowledge of the pleasant sensory experiences' patients have had throughout their life becomes a basic instrument (senso-biography: annex 3).

Regarding the presentation of stimuli, significant environmental immersion, including different sensory inputs, is one of the greatest potentialities of the Snoezelen room. In this sense, recent studies have investigated combinations of sensory inputs; for example, Flavian (2020) in a study on a young population, concludes that the addition of pleasant ambient scents congruent with audiovisual stimuli improves affective and behavioral responses.

We present a single case study as an example of SMS intervention in advanced dementia. As a qualitative study, it allows us to deepen our understanding of the behavior of a person as a whole and to give meaning to their world of relationship interactions with people, their motivations, and more (Fernández, 1999 in Pelekais, 2000).

First, an overview of the case at the beginning of the intervention is provided. To collect this information, two previous coordination meetings were held between professionals from the nursing home and the Snoezelen room. This is followed by the objectives that were set, the design, the intervention itself, and evaluation of the results.

\section{Case description}

The study involved an 88-year-old woman (M), who had been living in a nursing home for two years at the time of the intervention. In terms of biographical details, she was born in a large city, where she lived until adulthood. She studied until the age of 12 and dedicated her life to embroidery and helping the family run a grocery store. When 
the store closed, she took care of her nephews. She lived with her parents first, and then with her sister. When she was older, she moved to another city, where she lived with her niece until she entered the nursing home. Nowadays, she receives regular visits from her nieces and nephews, and they are her current family support.

The occupational therapist informed us that at first, $M$ had had difficulty adapting to the residence, with recurrent episodes of anxiety that she continues to show today; in addition to considerable emotional dependence on family members and professionals. Her characteristics include persistent motor ambulation, with high risk of fall due to gait instability. She requires individualized attention, both to perform activities of daily living $(A D L)$ and to regulate her emotional state and level of involvement.

In terms of physical health, she has arterial hypertension (controlled with medication), osteoporosis with bilateral knee replacement surgery, acquired hypothyroidism, insomnia, inguinal hernia, cataracts, and bilateral hypoacusis.

The diagnoses of interest for our study are, on the one hand, unspecified dementia (ICD10), GDS 6 with severe cognitive impairment (in the last year she has gone from a score of 15 in the MEC to a score of 0). In terms of mental health, she has panic disorder without agoraphobia, recurrent depressive disorder with a high level of anxiety (a score of 12 on the Cornell scale) and NPI (Cummings Neuropsychiatric Inventory) score of 28. The high level of anxiety manifests itself in compulsive wandering without specific purpose, and continuous agitation. Her state of alertness fluctuates, presenting as difficulty in paying attention and responding to her environment. Her score in the CohenMansfield Inventory of Agitation and Cognitive Impairment (CMAI) is 44, indicating verbal aggressiveness, constant demand for help, negativistic attitude, and complaints. He takes antidepressant and anxiolytic medication.

Regarding her senso-biography (information about her sensory preferences), M prefers tactile stimuli, especially those that have smooth and soft properties. She markedly seeks contact with people (possibly related to the dependence mentioned previously, since this may provide the security that she craves). She likes to feel welcomed and enveloped on a physical level, both by the embrace of people and by objects such as blankets and cushions. She prefers warm temperatures to cold. On a vestibular level, he finds rocking and certain smells pleasant, especially cosmetic products such as creams and perfumes, or drinks such as coffee. On an auditory level, she enjoys listening to music from her youth. The visual stimuli that interest her are autobiographically associated with her city, trips, and pleasant experiences with family members.

Once the initial assessment had been made, it was determined that the problems which caused the most overload among nursing home professionals and relatives, were the high level of agitation and anxiety that $\mathrm{M}$ presented, and her lack of involvement in the environment around her. 


\section{Objectives of the intervention in the Snoezelen room}

The general objectives of the Interdisciplinary Program of Individual Attention (IPAI) proposed by the professional team at the nursing home were:

- To regulate alertness

- To reduce the level of agitation and anxiety

Regarding the intervention in the Snoezelen room, the specific objectives agreed upon were:

1. To improve connection to the environment:

- fostering communication by promoting autobiographical memory processes through reminiscence

- increasing autonomy and participation

2. To reduce the level of agitation and anxiety:

- by means of relaxation

\section{Design of the Snoezelen Room Intervention}

A mixed research design was used, combining quantitative and qualitative methodologies. A unique case design of repeated measures, it included a post-test pre-test assessment. Physiological records and observational behavioral records were used for the evaluation. At the physiological level, the level of blood oxygen was recorded with a finger pulse meter (with a percentage of between $90 \%-99 \%$ considered adequate), and the heart rate was recorded in beats per minute (with normal frequency considered at between 50-100 beats per minute). Blood pressure was also recorded (with normal frequency considered to be between 8-12 points). During the sessions, a total of seven items were recorded in the behavioral profile: level of emotional well-being, level of relaxation, level of attention, level of communication, and level of motivation with Likert-type scores from 1 to 3 (see annex 2). Finally, post-intervention behavior was recorded after two hours, i.e., during the midday meal in the nursing home. The recording was carried out by a geriatric care provider, who had no knowledge of the intervention.

The first two sessions in the room with $\mathrm{M}$ were aimed at familiarizing her with its elements and establishing a sensory assessment according to the observational register proposed by Cid (2010) (see annex 1). This would allow us to choose sensory stimuli appropriate to her preferences and needs. Ten weekly sessions in the Snoezelen room were planned, from 11 a.m. to 11.45 a.m., accompanied by the occupational therapist (OT) of the nursing home. Due to health problems and the onset of the covid-19 pandemic, only five sessions were completed. In total, seven sessions with $\mathrm{M}$ were conducted nonconsecutively over a period of three months, between January to March 2020.

The following is a summary of her sensory profile (which contrasts in places with the information obtained in the senso-biography): $M$ had a positive reaction to and preference for visual stimuli in the form of images on the projection screen. 
She preferred soft lighting to bright. She showed interest in the optical fibers. She had a positive response to direct touch with people with whom she was affectionately connected, and a preference for soft and smooth textures. She was attracted to auditory stimuli, especially music that was meaningful to her. She responded to smells (especially olfactory stimuli that were familiar to her) and gustatory stimuli (taking into account her remaining ability to swallow certain foods). Finally, $M$ sought vestibular input through rocking herself when seated, and she willingly accepted being rocked by a professional, both on the waterbed and in the armchair.

\section{Development of the intervention}

To work on the Snoezelen room objectives (considering M's sensory preferences) we proposed:

Objective 1: stimulating communication by promoting autobiographical memory processes, using large screen projections of images reminiscent of her hometown and traditional festivals.

Objective 2: encouraging autonomy and participation, using the switchboard to make environmental changes, and to select content that appealed to her on the screen.

Objective 3: reducing anxiety levels through relaxation on the water bed, and tactile and vestibular stimulation through balancing, with the help of the therapist.

Each session consisted of three stages, the entrance ritual, the two phases of the session (i.e., relaxation and activation), and the closing ritual. The materials for the autobiographical memory activities included sewing paraphernalia (since her records suggested that she had sewn for a long time) and images, videos, and songs from traditional festivals of her city. In two of the five sessions, sewing paraphernalia was used, although in both cases the presented objects produced a negative response and aversion; therefore, we did not consider them able to evoke suitably positive memories for promoting well-being. From the images, videos and songs, $\mathrm{M}$ reacted particularly positively to the images (with relaxed facial expressions and vocalizations of pleasure in response to them); evidently, they were a way for $M$ to connect with the environment. Thanks to this, we were able to work on her verbal communication with others, and the evocation of songs, observing a clear impact on her willingness to initiate communication.

In two of the five sessions, olfactory stimulation was used with smells that $\mathrm{M}$ was expected to find pleasant (aromatic plants, hand cream, cologne); a particularly positive reaction was observed in response to visual, tactile, olfactory, and gustatory stimulation from coffee.

Gradually, it was possible to encourage in $\mathrm{M}$ a participatory attitude and greater autonomy in the room - from stretching out on the bed with the OT, to stretching out and remaining calm when left alone in the 2 nd session. M demonstrated an increased ability to interact with professionals, to express needs, and a willingness to try out new areas of the room (e.g., the armchair under the fiber shower, and elements such as the color switch), with the help of the therapist. 


\section{M using the color switch in the bubble tube}

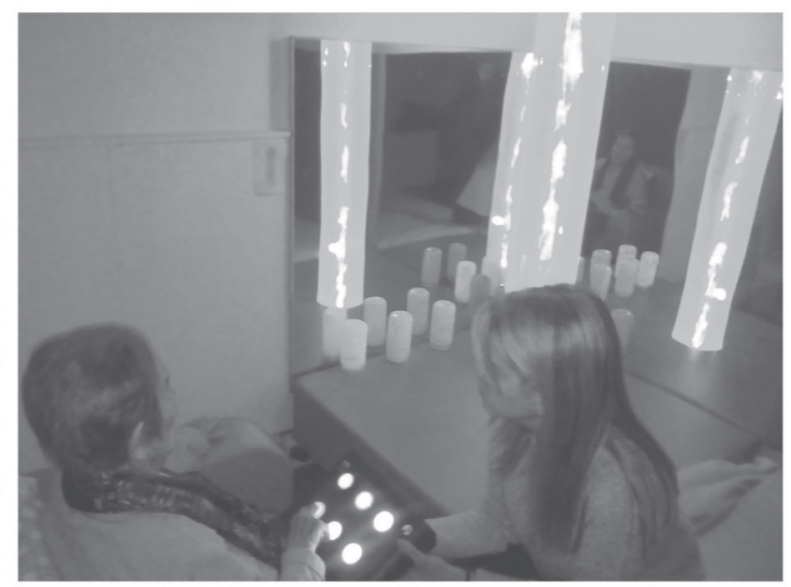

Regarding the intervention on anxiety, a first phase of relaxation was implemented in the five sessions, involving the waterbed and massage with moisturizing cream and soft textures. This produced a positive response, especially in areas of the body such as the face and hands. At a behavioral level, M became increasingly calmer in the room, and verbal expressions of needing to go to the toilet or to leave the room decreased.

A feeling of calm and tranquility was observed two hours after the intervention in the Snoezelen room, at mealtime in the nursing home. The geriatric care worker observed a reduction in compulsive eating behavior, associated with the higher levels of calmness on days when M had been in the Snoezelen room.

The results of the physiological and behavioral assessment are detailed below.

\section{Results}

In order to show objective data relating to level of anxiety (objective 3) and level of alertness during the sessions, Figure 1 displays the global values of the psychophysiological measurements pre-post session (except for the first session, in which the measurements could not be carried out, due to lack of cooperation).

A slight reduction was observed between pre- and post- session in the maximum and minimum blood pressure for all sessions. Oxygen levels remained above $90 \%$ saturation, and no significant pre-post changes were observed. Her heart rate in beats per minute had a tendency to increase slightly, possibly related to a higher level of alertness at the end of the session. 
Figure 1: Physiological measurements
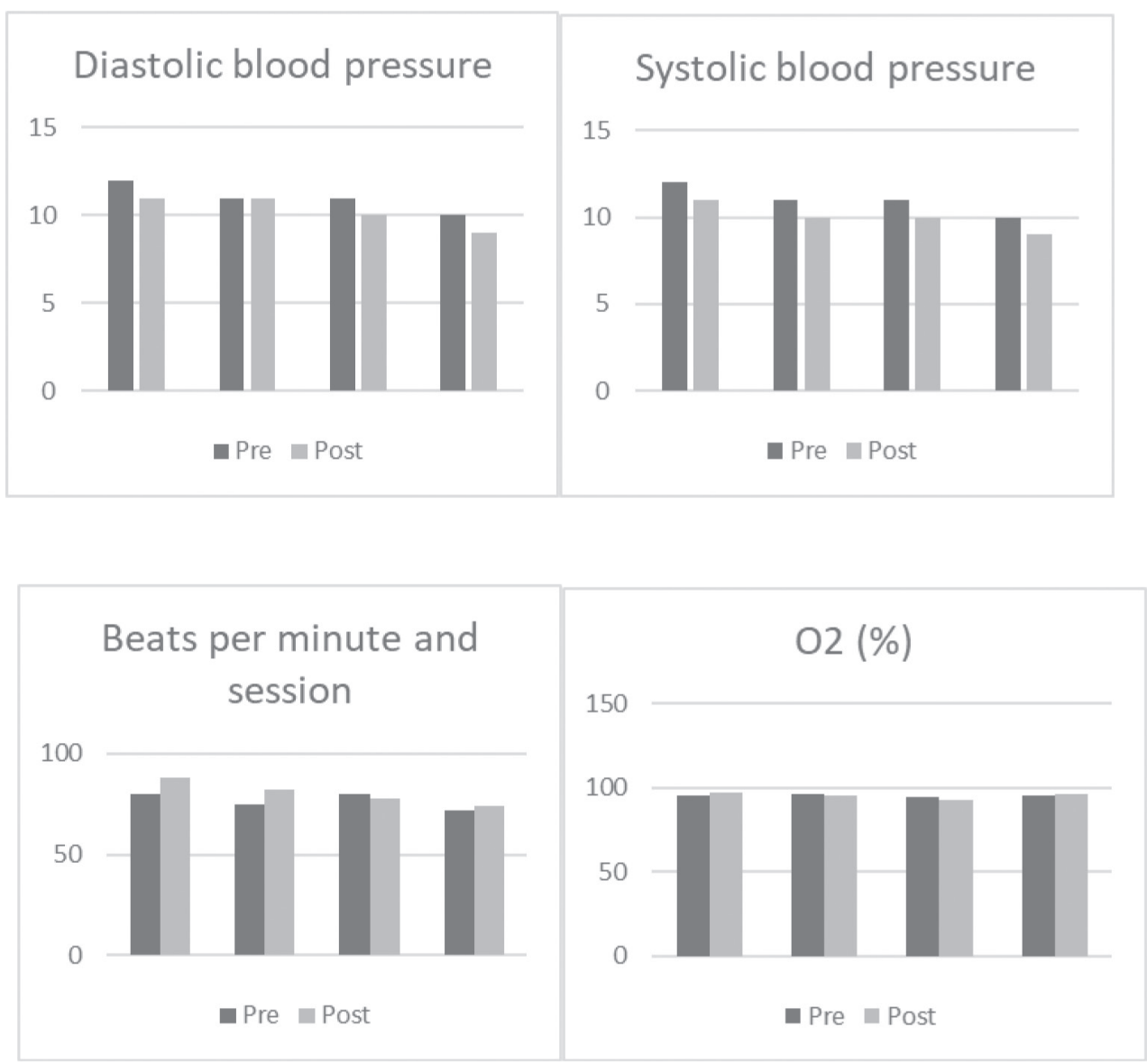
Figure 2 is a record of M's most notable general behaviors, pre-/post- session, and two hours post-session.

\section{Figure 2: Measurements of pre-/post- and $2 \mathrm{hrs}$ post- session behaviors}

\section{Behavior registration}

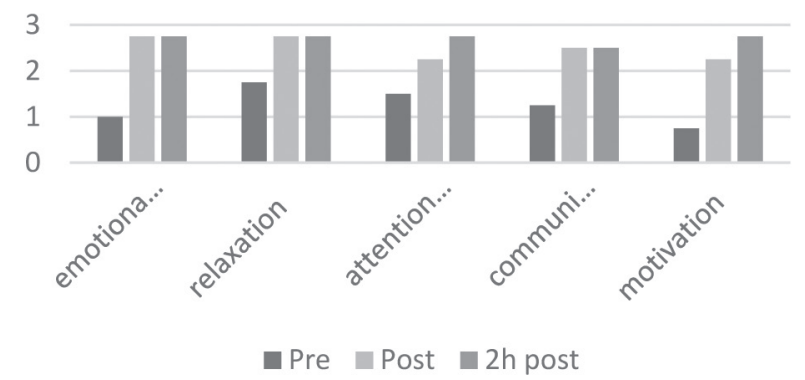

Broadlyspeaking, an increase inemotionalwell-being, relaxation, attention, communication, and motivation is observed pre-post session. Two hours after the intervention in the Snoezelen room, the level of well-being, relaxation, and communication was maintained, and levels of attention and motivation had increased; although this increase may be partly explained by the activity that took place at this time: i.e., the midday meal. During the different sessions, there were changes in M's state of health, which may have influenced the prevalence of certain behaviors. However, we observed more adaptive behaviors as we worked with $\mathrm{M}$ in the room, with clear differences between the beginning of the first session, in which we met a nervous, anxious $M$, almost incapable of relaxing, and the last session, in which $M$ was much calmer without needing to leave the room, and without constantly making demands on the therapist's attention.

\section{Discussion of results}

Regarding the first objective, it was very productive to work with reminiscence and autobiographical memory at a visual and auditory level. At the same time, these reminiscence activities made it easier for us to work on the other objectives. $M$ was attentive to the screen, albeit discontinuously. We also observed how M's language became much clearer and more understandable during the projection of images, and she had a greater facility to find appropriate words.

In terms of the second objective (autonomy and participation), we observed progress in M's ability to move around the room on her own (without needing to hold the therapist's arm), and her interest in using a switch to change the lighting. Above all we noted a reduction in the physical need to have the therapist constantly beside her. 
For the third objective (reduction of distress and anxiety through relaxation), the use of vestibular stimulation on the waterbed, together with tactile stimulation proved beneficial. Although at times $\mathrm{M}$ responded with reluctance to the stimuli. and showed displeasure, at a certain point a state of relaxation was achieved in all sessions, so that $M$ could enjoy moments of calm with the help of the occupational therapist. Her levels of well-being, relaxation, and communication were maintained two hours after the intervention.

\section{Conclusions}

The results analyzed are in line with those observed by Sposito et al. (2016), Maseda et al. (2018) and Aznar-Calvo et al. (2019). Although the results were not statistically significant, the Snoezelen intervention in this case study was effective in: improving the level of M's connection with the environment (indicating the subject to be more cognitively active), reducing her level of anxiety, and adjusting her behavior after the sessions and in the short term. Therefore, it is evident that a subject with more severe cognitive impairment can respond positively to structured and sensorially stimulating environments, reducing the behavioral symptomatology of dementia.

Regarding the methodology, the Person-Centered Care model was confirmed as a principle of personalized comprehensive care in professional intervention. We agree with Jakob and Collier (2017) regarding the need for the meaningfulness of the activities linked to patients' life history, and the need to allow patients the fullest possible control over interaction in the room, in line with their abilities. Regarding the presentation of stimuli, we agree with Flavián (2020) that meaningful environmental immersion, including the various sensory inputs congruent with immersion, is a major potentiality of the Snoezelen room.

Obviously, from an experimental research design perspective with quantitative methods, a case study presents important limitations; however, the difficulty of working with large samples of people with advanced dementias (GDS6/7) due to their fragile overall state of health and behavioral problems should be kept in mind. For this reason, we decided on a complementary methodology, combining quantitative and qualitative aspects. The case study allowed us to study a particular situation in depth, in order to understand the development of a Snoezelen intervention and its potential benefits.

\section{References}

Aznar-Calvo, A., Vaca-Bermejo, R., Martínez-Longares, P., Villa-Berges, E., EsplugaBarquero, S., Pozo-Lafuente, A., \& Ancizu-García, I. (2019). Multisensory stimulation in residential centers: a non-pharmacological therapy that improves the connection with the environment. Psychogeriatrics, 9(1), 11-17. 
Cid Rodríguez, M. J. (2010). Multisensory stimulation in a Snoezelen space: concept and fields of application. Revista Española sobre Discapacidad Intelectual, 41 (4), 22-32.

Cid Rodríguez, M. J. (2012). Multisensory Stimulation in a Snoezelen Space. Madrid: Editorial Academia Española.

Flavián, C., Ibáñez-Sánchez, S., \& Orús, C. (2020). The influence of scent on virtual reality experiences: The role of aroma-content congruence. Journal of Business Research, 123, 289-301. doi.org/10.1016/j.jbusres.2020.09.036

Jakob, A., \& Collier, L. (2017). Sensory enrichment for people living with dementia: increasing the benefits of multisensory environments in dementia care through design. Design for Health, 1(1), 115-133. doi:10.1080/24735132.2017.1296274

Lazarus, A. (2009). The multisensory classroom in an educational center: Curricular aspects and practical applications. University of Murcia, 1-16.

Maseda, A., Cibeira, N., Lorenzo-López, L., González-Abraldes, I., Buján, A., de Labra, C., \& Millán-Calenti, J. C. (2018). Multisensory Stimulation and Individualized Music Sessions on Older Adults with Severe Dementia: Effects on Mood, Behavior, and Biomedical Parameters. Journal of Alzheimer's Disease, 63(4), 1415-1425. doi:10.3233/jad-180109

World Health Organization (2015). International Classification of Diseases: Mental and Behavioral Disorders (10th ed).

Pelekais, C. (2000). Quantitative and qualitative methods: differences and trends. Telos, 2(2), 347-352.

Kitwood, T. (1997) Dementia reconsidered: the person comes first. Open University Press, Buckingham (translation from 2003. Rethinking dementia. For people's rights. Eumo Editorial. Vic.)

Sposito, G., Barbosa, A., Figueiredo, D., Yassuda, M. S., \& Marques, A. (2016). Effects of multisensory and motor stimulation on the behavior of people with dementia. Dementia, 16(3), 344-359. doi:10.1177/1471301215592080 


\section{Authors}

Ribes, Ramona

Professor in the department of psychology. Faculty of education, psychology and social work. University of Lleida.

avd. Estudi General, n4. CP.25180. Lleida. Spain

ramona.ribes@udl.cat

Maria José Cid

Psychologist, coordinator ISNA Spain, collaborator University of Lleida.

C/Major, n53. CP43570. Santa Bàrbara. Tarragona. Spain

mariajosecidrodriguez1964@gmail.com

Noelia Llamas

Nursing home psychologist, Lleida, Spain

\section{Annexes}

(1) Assessment of M's sensory profile

(2) Behavioral observational record

(3) Information from M's senso-biography 


\section{(1) Assessment of M's Sensory Profile in the Snoezelen Room}

\begin{tabular}{|c|c|}
\hline Visual & $\begin{array}{l}\text { In terms of reaction to and fixation on a luminous object, } \mathrm{M} \text { has } \\
\text { an ocular response to light, although light that is overly bright can } \\
\text { irritate her, prompting an avoidance response. She keeps her gaze } \\
\text { fixed, and does not visually track any of the light intensities. }\end{array}$ \\
\hline auditory & $\begin{array}{l}\text { M. showed no reaction to weak auditory stimuli, although she did } \\
\text { react to strong stimuli, both from the human voice and music, which } \\
\text { she tries to locate, and in the case of the human voice, is compelled } \\
\text { to approach. } \\
\text { We can relate her non-reaction to weak stimuli to auditory dysfunction, } \\
\text { while her approaching of interlocuters and looking at them when they } \\
\text { speak to her could be attributed to her need for physical contact } \\
\text { and "protection". }\end{array}$ \\
\hline olfactory & $\begin{array}{l}\text { In terms of olfactory stimuli, M. responded by approaching the scents. } \\
\text { She showed a preference for the stimuli of coffee and chocolate, } \\
\text { responding to them with pleasure; while we observed an indifference } \\
\text { to mint, lavender and cologne (although cologne appears in her } \\
\text { senso-biography as a smell she that likes). }\end{array}$ \\
\hline taste & $\begin{array}{l}\text { M. responded very positively to the taste stimuli of coffee } \\
\text { and chocolate, seeming to want more. She does not like the sour } \\
\text { taste of lemon, which causes her to close her eyes tightly. } \\
\text { *According to her senso-biography, she is reported to have been } \\
\text { very keen on coffee and similar products, although, the occupational } \\
\text { therapist observed that she drank coffee only sporadically. }\end{array}$ \\
\hline tactile & $\begin{array}{l}\text { We obtained a negative response to aversive stimuli such as pressure } \\
\text { or friction from rough materials. M. accepts soft blankets and cushions. } \\
\text { She often seeks contact with people by holding their hands and arms } \\
\text { when they are nearby; therefore, we consider contact with others } \\
\text { to be a positive stimulus. }\end{array}$ \\
\hline vestibular & $\begin{array}{l}\text { We observed a slight positive response to frontal and lateral } \\
\text { rocking. According to the information provided by the OT, she } \\
\text { has a tendencyto rock back and forth to relax, and does the same } \\
\text { on the lap of the OT when she is nervous and agitated (this rocking } \\
\text { is reminiscent of a mother rocking her child in her arms, providing } \\
\text { protection and skin-to-skin contact to transmit a sense of security). }\end{array}$ \\
\hline Proprioceptive & $\begin{array}{l}\text { She showed no reaction to pressure applied for a few seconds to her } \\
\text { arms and hips, although we observed a certain aversion when we } \\
\text { passed a hand gently over her legs and feet. } \\
\text { * It should be noted that } M \text { has small wounds on the skin of her arms } \\
\text { and legs, a fact that may cause a degree of sensitivity and aversion } \\
\text { to touch there. }\end{array}$ \\
\hline
\end{tabular}




\section{Behavioral observational record (from Lazarus, 2009)}

\begin{tabular}{|c|c|}
\hline $\begin{array}{l}\text { Emotional well- } \\
\text { being }\end{array}$ & $\begin{array}{l}\text { When a person shows signs of being at ease, expresses pleasure, } \\
\text { enjoys bonding with other adults, and smiles }\end{array}$ \\
\hline $\begin{array}{l}\text { Adapted } \\
\text { behaviors }\end{array}$ & $\begin{array}{l}\text { Behaviors that do not distort one's functioning or interaction } \\
\text { with others. Absence of self-harm, aggression towards adults, } \\
\text { and destruction of objects }\end{array}$ \\
\hline $\begin{array}{l}\text { Degree } \\
\text { of relaxation }\end{array}$ & A general state of stillness and calm, movements cease \\
\hline $\begin{array}{l}\text { Control } \\
\text { of stereotypical } \\
\text { movements }\end{array}$ & $\begin{array}{l}\text { Decrease in the frequency of very repetitive, impulsive, rhythmic, self- } \\
\text { stimulating, or self-soothing movements which have some utility for } \\
\text { the individual }\end{array}$ \\
\hline $\begin{array}{l}\text { Attentional } \\
\text { level }\end{array}$ & $\begin{array}{l}\text { Attention span in the room, i.e., whether he/she focuses on what } \\
\text { is being done; whether he/she constantly moves from one device } \\
\text { to another; whether he/she seems restless or agitated }\end{array}$ \\
\hline $\begin{array}{l}\text { Level } \\
\text { of communi- } \\
\text { cation }\end{array}$ & $\begin{array}{l}\text { Whether the person shows interest in or interaction with others; } \\
\text { whether he/she addresses others; whether he/she seeks visual, tactile, } \\
\text { proprioceptive contact with others; whether he/she makes gestures } \\
\text { of rapprochement, of seeking bodily contact, or gives warm looks }\end{array}$ \\
\hline $\begin{array}{l}\text { Level } \\
\text { of motivation }\end{array}$ & $\begin{array}{l}\text { Assessment of the internal state of the subject in relation to being } \\
\text { in the multisensory room. Whether it is apparent he/she wants to go } \\
\text { there; whether he/she is comfortable there; whether he/she shows } \\
\text { interest in staying longer in the room }\end{array}$ \\
\hline
\end{tabular}

\section{Sensio-biography}

\section{Tactile and Somatic Perception}

- Side: right

- She prefers warm water for showering, natural water for drinking.

- She likes soft clothing textures; she rejects rough materials.

- She is not usually bothered by her clothes, but lately she becomes distressed if she wears too many clothes.

- She likes bodily contact very much and being touched. She enjoys intense hugs very much.

- She likes being touched most on her hands; she does not like being touched on the face very much.

- She likes to have her hair touched. She loves going to the hairdresser.

- She likes the hot air from hair dryers. She does not like fans.

- She likes to feel contact with soft natural elements, such as sand and grass. 


\section{Proprioception}

- She likes walking very much, although she needs to be accompanied, due to problems with balance.

- She is currently denied this opportunity due to high risk of fall. When she is very agitated, she wears an abdominal restraint.

- She had always previously enjoyed swimming in a pool with friends and family, but it now seems to cause her more distress than pleasure.

- She has never played any sports, but she has always been very keen on watching football (on TV).

- The application of any strong pressure causes her pain.

- She does not like going barefoot indoors.

- She likes to cover herself up in bed, feeling enveloped. She does not usually move during the night.

- She does not use crutches or other supports to maintain her posture.

- No stereotypes appear.

\section{Vestibular}

- She likes gentle rocking very much; it calms and reassures her. She does not usually get dizzy.

- She usually sits with her legs parallel.

- At first, she showed reluctance, but she is beginning to tolerate it more and more.

\section{Olfactory Perception}

- She likes the scent of perfumes (e.g., DKNY).

- She shows no interest in flowers or their smells.

- She likes moisturizing creams (e.g., Nivea and an olive cream by Mercadona).

- She generally likes the smell of food (e.g., peaches and coffee).

- She has a good sense of smell.

\section{Taste Perception}

- She likes soups, potato tortillas, and chorizo. She rejects mashed/pureed foods.

- She prefers drinks at room temperature.

- She likes coffee with milk and tonic.

- She does not require help with feeding. 


\section{Auditory Perception}

- Her hearing is becoming increasingly impaired. She frequently has ear wax blockages.

- She has always enjoyed listening to the radio.

- She likes anything connected with the royal family and celebrity gossip magazines.

- Musically, she likes zarzuela, folk songs, Luis Mariano, and Viennese Christmas concerts.

\section{Visual Perception}

- She likes to look at old family photographs.

- She likes to watch movies, although it is getting increasingly harder for her to concentrate on them and follow the story. Her favorites are: Gone with the Wind", and the musicals "The Sound of Music ", and "Mama Mia". She also likes TV entertainment shows.

- She has never had a favorite color.

- She fondly remembers a trip to Madrid by train.

- $\mathrm{M}$ is more of a daytime person; she has always been an early riser. She finds it difficult to sleep at night. 